\title{
Interação entre inoculação com rizóbio e adubação nitrogenada de plantio na produtividade do feijoeiro nas épocas da seca e das águas
}

\section{Interaction between rizobial inoculation and sowing nitrogen fertilization on yield of common bean crop at dry and rainy seasons}

\author{
Rodrigo Luiz Neves Barros ${ }^{1}$; Leandro Barbosa de Oliveira ${ }^{1}$; \\ Welliton Barros de Magalhães ${ }^{2}$, Leonardo Oliveira Médici³ ${ }^{3}$ Carlos Pimentel ${ }^{4^{*}}$
}

Resumo

O objetivo do trabalho foi avaliar o efeito da interação entre a inoculação com rizóbio e a adubação nitrogenada de plantio no feijoeiro (Phaseolus vulgaris L.). Os experimentos de campo com a cultivar Ouro Negro, nas épocas da seca e das águas, tiveram três tratamentos: inoculação e adubação nitrogenada no plantio $\left(20 \mathrm{~kg} \mathrm{ha}^{-1}\right.$ de $\left.\mathrm{N}\right)$, apenas a inoculação no plantio, e apenas a adubação nitrogenada no plantio $\left(20 \mathrm{~kg} \mathrm{ha}^{-1}\right.$ de N). Todos os tratamentos receberam adubação de cobertura com $40 \mathrm{~kg} \mathrm{ha}^{-1}$ de N. No florescimento, avaliou-se a massa seca de parte a aérea e de raiz e o número e massa seca de nódulos. Obteve-se maior massa seca de parte aérea no tratamento adubado e inoculado, sendo o número e massa seca de nódulos similares ao tratamento só inoculado, nas duas épocas de plantio. Na maturação, nas duas épocas, a maior produtividade de grãos e o maior número de vagens e de grãos por planta, foram obtidos no tratamento adubado e inoculado, sendo que os tratamentos só inoculado e só adubado não diferiram significativamente. Portanto, a inoculação de rizóbios no plantio pode substituir a adubação nitrogenada com $20 \mathrm{~kg} \mathrm{ha}^{-1}$ de $\mathrm{N}$ no plantio sem perda de produtividade. Além disto, a inoculação com rizóbios, acrescida da adubação com $20 \mathrm{~kg} \mathrm{ha}^{-1}$ de $\mathrm{N}$ no plantio, não inibiu a nodulação e propiciou acréscimo de produtividade.

Palavras-chave: Nodulação, Phaseolus vulgaris, Rhizobium, produtividade

\begin{abstract}
This work has the objective of evaluating the effects of the interaction between inoculation with Rhizobium strains and nitrogen fertilization at sowing on common bean (Phaseolus vulgaris L.) crop. The field experiments with the cultivar Ouro Negro, at dry and rainy seasons, had three treatments: inoculation and sowing $\mathrm{N}$ fertilization $\left(20 \mathrm{~kg} \mathrm{ha}^{-1}\right.$ of $\left.\mathrm{N}\right)$, only the inoculation, and only sowing $\mathrm{N}$ fertilization $\left(20 \mathrm{~kg} \mathrm{ha}^{-1}\right.$ of $\left.\mathrm{N}\right)$. Every treatment received $40 \mathrm{~kg} \mathrm{ha}^{-1}$ of $\mathrm{N}$ by covering. At flowering, the shoot and root dry weight and nodules number and dry weight were evaluated. The higher shoot dry weight was obtained for the inoculation and sowing $\mathrm{N}$ fertilization treatment, with similar number and dry weight of nodules of the only inoculation treatment, for both seasons. At the maturity, the higher grain yield, number of pods and grains per plant, were obtained for the inoculation and sowing $\mathrm{N}$ fertilization treatment, whereas only inoculation and only sowing $\mathrm{N}$ fertilization treatments were not significantly different. Therefore, inoculation can substitute sowing $\mathrm{N}$ fertilization with $20 \mathrm{~kg} \mathrm{ha}^{-1}$ of N with the same yield. Also, the sowing $\mathrm{N}$ fertilization together with inoculation did not inhibit nodulation and improved yield.
\end{abstract}

Key words: Nodulation, Phaseolus vulgaris, Rhizobium, yield

1 Discentes de Mestrado do Programa de Pós-graduação em Fitotecnia, Universidade Federal Rural do Rio de Janeiro, UFRRJ, Seropédica, RJ. E-mail: rbf7ufrrj@hotmail.com; leufrrj@yahoo.com.br

2 Discente de graduação em Engenharia Agronômica, UFRRJ, Seropédica, RJ. E-mail: wellitonbarros@yahoo.com.br

3 Prof. Adjunto do Dept ${ }^{\circ}$ de Ciências Fisiológicas, Instituto de Química, UFRRJ, Seropédica, RJ. E-mail: lmedici@gmail.com

4 Prof. Titular do Dept ${ }^{\text {o }}$ de Fitotecnia, Instituto de Agronomia, UFRRJ, Seropédica, RJ. E-mail: greenman@amcham.com.br

* Autor para correspondência 


\section{Introdução}

O feijão comum (Phaseolus vulgaris L.) é a mais importante fonte de proteínas para as populações de baixa renda, na América Latina e também no Sul e Oeste da África (TORRES et al., 2009), sendo a dieta básica e fonte de proteína e sais minerais de menor custo para o brasileiro (COSTA et al., 2006). Dentro do contexto de agricultura com baixo uso de insumos, destaca-se a necessidade do desenvolvimento de tecnologias de baixo custo capazes de melhorar os níveis de produtividade dos pequenos agricultores (HAWERROTH; CRESTANI; SANTOS, 2011) para a produção desta leguminosa importante para a sua subsistência (GRANGE et al., 2007).

O nitrogênio é o macronutriente absorvido em maior quantidade pela cultura do feijoeiro e sua disponibilidade tem influência significativa na produtividade (SILVA et al., 2000). Por isto, o manejo adequado da adubação nitrogenada representa uma das principais dificuldades da cultura do feijoeiro, visto que a aplicação em quantidade insuficiente pode limitar o seu potencial produtivo, mesmo que outros fatores de produção estejam otimizados; e a sua utilização em doses excessivas, além de aumentar o custo econômico, pode promover riscos ao ambiente (SANTOS et al., 2003). Contudo, esta cultura pode obter parte do nitrogênio necessário ao seu crescimento por meio da associação simbiótica com bactérias do gênero Rhizobium, que utilizam o $\mathrm{N}_{2}$ atmosférico, por meio da ação do complexo enzimático nitrogenase (GRAHAM; VANCE, 2000). O rizóbio, neste sistema de simbiose, utiliza os carboidratos provenientes da fotossíntese da planta hospedeira para sua manutenção e promover o processo de Fixação Biológica de $\mathrm{N}_{2}(\mathrm{FBN})$; e por outro lado, a planta se beneficia do nitrogênio fixado pela bactéria (STRALIOTTO, 2002).

Assim, a associação do feijoeiro com espécies de bactérias do grupo dos rizóbios, principalmente Rhizobium tropici, é uma tecnologia capaz de substituir a adubação nitrogenada, reduzindo o custo de produção do cultivo (GRANGE et al.,
2007). Por outro lado, o nitrogênio no solo é um nutriente cuja presença ou ausência afeta a simbiose de várias formas (VIEIRA; TSAI; TEXEIRA, 2005). Em excesso, o fertilizante nitrogenado pode causar uma diminuição da eficiência simbiótica, porém quando aplicado em pequenas quantidades, na semeadura da cultura do feijoeiro, permite um aumento no crescimento dos nódulos e maior FBN, sendo que o teor muito baixo de $\mathrm{N}$ no solo pode até ser limitante à atividade simbiótica (HUNGRIA; CAMPO; MENDES, 2003). Contudo, estudos realizados por Voisin et al. (2003) mostraram que a adição de nitrato em solução nutritiva, em doses inibitórias para a FBN da ervilha, diminuiu a massa seca dos nódulos, porém a atividade específica da nitrogenase se manteve.

O estudo sobre a interação nitrogênio mineral e inoculação com rizóbios para o feijoeiro, com doses de nitrogênio normalmente aplicadas (VIEIRA; TSAI; TEXEIRA, 2005), poderá contribuir para o aumento da eficiência de uso de nutrientes e produtividade na cultura. O presente trabalho teve como objetivo avaliar o efeito da interação entre a inoculação com rizóbio e a adubação nitrogenada na produtividade da cultura do feijoeiro, cultivar Ouro Negro, na época da seca e das águas.

\section{Material e Métodos}

Foram instalados dois experimentos no Campo Experimental do Departamento de Fitotecnia, da Universidade Federal Rural do Rio de Janeiro, a $22^{\circ} 45^{\prime} \mathrm{S}, 43^{\circ} 41^{\prime} \mathrm{W}$ e $40 \mathrm{~m}$ de altitude. O clima da região é do tipo Aw, segundo a classificação de Köppen, com verão quente e chuvoso e inverno seco. O primeiro experimento foi instalado no mês de maio de 2010, no plantio da seca, em um Argissolo Vermelho Amarelo, cuja análise química, na profundidade de $0-20 \mathrm{~cm}$, efetuada de acordo com a descrição de Claessen (1997), revelou: $\mathrm{pH}$ em água 5,7; 2,6 $\mathrm{cmol}_{\mathrm{c}} \mathrm{dm}^{-3}$ de $\mathrm{Ca} ; 1,5 \mathrm{cmol}_{\mathrm{c}} \mathrm{dm}^{-3}$ de $\mathrm{Mg} ; 0,5 \mathrm{cmol}_{\mathrm{c}} \mathrm{dm}^{-3}$ de Al; $1,3 \mathrm{cmol}_{\mathrm{c}} \mathrm{dm}^{-3} \mathrm{de} \mathrm{H}+$ $\mathrm{Al} ; 36 \mathrm{mg} \mathrm{dm}^{-3}$ de $\mathrm{P}$ disponível; 8,0 $\mathrm{mg} \mathrm{dm}^{-3}$ de $\mathrm{K}$ 
disponível; 10,5 $\mathrm{g} \mathrm{kg}^{-1}$ de matéria orgânica; e $76 \%$ de saturação de bases (V). A precipitação total, a evaporação total e a temperatura média da máxima e mínima, durante o experimento, foram de $264,4 \mathrm{~mm}$, $314,3 \mathrm{~mm}, 27,04{ }^{\circ} \mathrm{C}$ e $16,51{ }^{\circ} \mathrm{C}$, respectivamente. O segundo experimento foi instalado no mês de setembro de 2010, no plantio das águas, em um Argissolo Vermelho Amarelo, cuja analise química na profundidade de 0-20 cm (CLAESSEN, 1997), revelou: $\mathrm{pH}$ em água 5,$3 ; 1,5 \mathrm{cmol}_{\mathrm{c}} \mathrm{dm}^{-3} \mathrm{de} \mathrm{Ca} ; 0,5$

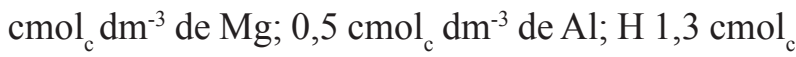
$\mathrm{dm}^{-3}$ de $\mathrm{H}+\mathrm{Al} ; 4 \mathrm{mg} \mathrm{dm}^{-3}$ de P disponível; 6,0 mg $\mathrm{dm}^{-3}$ de $\mathrm{K}$ disponível; $8 \mathrm{~g} \mathrm{~kg}^{-1} \mathrm{de}$ matéria orgânica; e $86 \%$ de saturação de bases (V). A precipitação total, a evaporação total e a temperatura média da máxima e mínima, durante o experimento, foram de 424,8 $\mathrm{mm}, 435,1 \mathrm{~mm}, 29,2{ }^{\circ} \mathrm{Ce} 20,2{ }^{\circ} \mathrm{C}$, respectivamente.

$\mathrm{O}$ delineamento experimental utilizado foi de blocos ao acaso, com três tratamentos e quatro repetições, com a cultivar Ouro Negro, de tegumento preto e hábito de crescimento indeterminado prostrado. Cada parcela foi constituída por cinco linhas de $5 \mathrm{~m}$ de comprimento espaçadas em $0,5 \mathrm{~m}$, com $10 \mathrm{~m}^{2}$ de área por parcela. Os três tratamentos estudados foram: inoculação e adubação nitrogenada no plantio (20 kg ha-1 de N), apenas a inoculação no plantio, e apenas a adubação nitrogenada no plantio (20 kg ha-1 de N), na forma de ureia. Todos os tratamentos receberam adubação de cobertura com $40 \mathrm{~kg} \mathrm{ha}^{-1}$ de $\mathrm{N}$.

O preparo do solo foi constituído por uma aração e uma gradagem leve, seguido pela abertura dos sulcos mecanicamente. Os tratamentos receberam adubação de $30 \mathrm{~kg}$ ha-1 de $\mathrm{P}_{2} \mathrm{O}_{5}$ (superfosfato simples) e $45 \mathrm{~kg} \mathrm{ha}^{-1}$ de $\mathrm{K}_{2} \mathrm{O}$ (cloreto de potássio), aplicados no sulco de plantio, de acordo com os resultados da análise de solo, em concordância com a recomendação e exigência da cultura (OLIVEIRA, ARAÚJO; DUTRA, 1996). A semeadura foi realizada manualmente, obtendo-se um estande final de 12 plantas por metro linear. Nos tratamentos com inoculação, as sementes foram inoculadas com estirpes de Rhizobium tropici, presentes no inoculante comercial obtido na Embrapa Agrobiologia. Após inoculadas, as sementes foram secas à sombra e depois semeadas nos sulcos de plantio. Aos 25 dias após a semeadura, foi feita em todos os tratamentos uma adubação nitrogenada em cobertura, com $40 \mathrm{~kg}$ ha $^{-1}$ de N (SORATTO; CARVALHO; ARF, 2005), na forma de uréia. Durante o desenvolvimento da cultura foram realizadas capinas manuais e irrigação quando necessária.

Aos 35 dias após o plantio, na floração plena, ocasião em que as parcelas apresentaram 50\% de flores abertas (VIEIRA et al., 2008), foram coletadas três plantas ao acaso, por parcela, utilizando-se uma pá reta como auxílio para arranque das plantas. A parte aérea e raiz foram secas em estufa de ventilação forçada, a $65{ }^{\circ} \mathrm{C}$ por $72 \mathrm{~h}$, para a determinação da massa seca. Os nódulos foram destacados das raízes, contados e secos em estufa, a $65^{\circ} \mathrm{C}$ por $48 \mathrm{~h}$, para quantificação da sua massa seca. Na maturação fisiológica, foram coletadas todas as plantas das duas linhas centrais de cada parcela, desprezando a ultima planta de cada lado destas linhas centrais, para determinação do número de vagens por planta, número de grãos por planta, massa de 100 grãos e produtividade de grãos.

Os dados de massa seca de nódulos foram transformados pela função $\sqrt{x+1}$, e foi realizada a análise de variância para todas as variáveis estudadas e, quando detectada significância entre tratamentos, a comparação entre as médias foi feita pelo teste de Tukey, a 5\% de probabilidade.

\section{Resultados e Discussão}

Em relação ao número e massa de nódulos, houve diferença significativa entre os tratamentos, nas duas épocas de cultivos (Tabela 1). Os maiores valores de número de nódulos foram observados no tratamento inoculado e no adubado e inoculado, nas duas épocas, sendo que apenas o inoculado foi superior ao tratamento só adubado, que por sua vez foi semelhante ao adubado e inoculado, também nas 
duas épocas. Quanto à massa de nódulos, não houve diferença significativa entre os tratamentos, nas duas épocas de plantio. Isso evidencia que a aplicação de $20 \mathrm{~kg} \mathrm{ha}^{-1}$ de $\mathrm{N}$ no plantio não inibiu o processo de nodulação da população de rizóbios inoculados. Isso também foi observado por Hungria, Campo e Mendes, (2003), com a aplicação de $15 \mathrm{~kg} \mathrm{ha}^{-1}$ de $\mathrm{N}$ no plantio do feijoeiro em campo, mas com uma dose de $30 \mathrm{~kg} \mathrm{ha}^{-1}$ de $\mathrm{N}$ no plantio estes autores observaram redução na nodulação. Oliveira, Araújo e Dutra (1996) afirmam que mesmo aplicando 100 $\mathrm{kg}$ de $\mathrm{N} \mathrm{ha}^{-1}$, ainda haverá uma contribuição da FBN para a nutrição do feijoeiro. Por outro lado, estes resultados referentes à nodulação contradizem alguns encontrados na literatura, relatando que mesmo baixas quantidades de $\mathrm{N}$ são capazes de inibir a nodulação em feijoeiro (ROMANINI JUNIOR et al., 2007). Entretanto, pode-se observar que no tratamento que não foi inoculado também houve nodulação, e o seu número de nódulos foi igual ao tratamento adubado e inoculado, nas duas épocas de plantio (Tabela 1), provavelmente devido à presença de estirpes nativas no solo nodulando o feijoeiro. Vieira, Tsai e Texeira (2005) também verificaram a nodulação do feijoeiro não inoculado, devido à presença de população nativa de rizóbios no solo. Contudo, existem diferenças na capacidade de realizar FBN entre as bactérias que fazem simbiose com o feijoeiro, assim como entre genótipos de feijoeiro (HAWERROTH; CRESTANI; SANTOS, 2011), que necessitam ser mais bem estudadas (GRANGE et al., 2007).

Tabela 1. Massa seca da parte aérea, massa seca de raiz, número de nódulos e massa seca de nódulos por planta do feijoeiro Ouro Negro, no estádio de florescimento, cultivado na época da seca e das águas.

\begin{tabular}{lcccc}
\hline Tratamentos & $\begin{array}{c}\text { Numero de } \\
\text { nódulos }\end{array}$ & $\begin{array}{c}\text { Massa seca de } \\
\text { nódulos (g)* }\end{array}$ & $\begin{array}{c}\text { Massa seca da } \\
\text { parte aérea (g) }\end{array}$ & $\begin{array}{c}\text { Massa seca de } \\
\text { raiz (g) }\end{array}$ \\
\hline & & Época da seca & & \\
Adubado & $20 \mathrm{~b}$ & $0,0106 \mathrm{a}$ & $6,1 \mathrm{~b}$ & $0,656 \mathrm{a}$ \\
Inoculado & $29 \mathrm{a}$ & $0,0204 \mathrm{a}$ & $6,3 \mathrm{~b}$ & $0,621 \mathrm{a}$ \\
Adubado e inoculado & $27 \mathrm{ab}$ & $0,0179 \mathrm{a}$ & $7,0 \mathrm{a}$ & $0,612 \mathrm{a}$ \\
Média & 25 & 0,0163 & 6,5 & 0,629 \\
CV (\%) & 10,64 & 6,34 & 12,6 & 8,12 \\
\hline & & Época das águas & & \\
Adubado & $25,6 \mathrm{~b}$ & $0,0137 \mathrm{a}$ & $6,2 \mathrm{~b}$ & $0,647 \mathrm{a}$ \\
Inoculado & $38,3 \mathrm{a}$ & $0,0269 \mathrm{a}$ & $6,5 \mathrm{~b}$ & $0,695 \mathrm{a}$ \\
Adubado e inoculado & $33,0 \mathrm{ab}$ & $0,0221 \mathrm{a}$ & $7,3 \mathrm{a}$ & $0,662 \mathrm{a}$ \\
Média & 32,3 & 0,0209 & 6,6 & 0,668 \\
CV (\%) & 13,25 & 7,71 & 7,01 & 8,29 \\
\hline
\end{tabular}

Dados transformados pela função $\sqrt{x+1}$. Médias seguidas pela mesma letra não diferem entre si pelo teste de Tukey $(\mathrm{P}<0,05)$. Fonte: Elaboração dos autores.

Quanto à produção de massa seca da parte aérea, também foi detectada diferença significativa entre os diferentes tratamentos, nas duas épocas de cultivo (Tabela 1). O tratamento adubado e inoculado foi superior aos dois outros tratamentos, o adubado e o inoculado, que tiveram valores semelhantes entre si, nas duas épocas. Portanto, o tratamento inoculado, sem adubação nitrogenada no plantio, permitiu uma produção de massa seca da parte aérea equivalente ao tratamento adubado. Isto demonstra que a capacidade de fornecimento de $\mathrm{N}$, para o acúmulo de massa, pela inoculação com rizóbio, é comparável ao do adubo nitrogenado no plantio, mas baixando o custo de produção. Em geral, as 
respostas do feijoeiro à adubação nitrogenada e à inoculação têm sido bastante variáveis (HUNGRIA; CAMPO; MENDES, 2003), quanto à produção de massa seca de parte aérea, sendo observados efeitos positivos (CARVALHO et al., 2001) ou sem efeitos significativos (FARINELLI et al., 2006). Contudo, no presente trabalho, a utilização em conjunto das duas fontes de $\mathrm{N}$, adubação mineral, com $20 \mathrm{~kg} \mathrm{ha}^{-1}$ de $\mathrm{N}$ no plantio e $40 \mathrm{~kg} \mathrm{ha}^{-1}$ de $\mathrm{N}$ na pré-floração, e inoculação com rizóbios, contribuiu para obtenção de maior massa seca de parte aérea no tratamento adubado e inoculado. Para massa seca de raiz não foi verificado efeito entre os tratamentos, nas duas épocas de cultivo, o que também foi observado por Valadão et al. (2009).

Quanto ao número de vagens por planta, foi observada diferença significativa entre os tratamentos (Tabela 2). O maior valor de número de vagens por planta foi obtido no tratamento adubado e inoculado, em relação aos demais tratamentos, nas duas épocas de cultivo. Os valores médios encontrados do número de vagens por planta são semelhantes aos de Ferreira et al. (2000), com a utilização de inoculante e nitrogênio mineral no plantio, que encontraram valor médio de 7,6 vagens por planta. Para o número de grãos por planta, também ocorrem diferenças significativas, e os valores obtidos no tratamento adubado e inoculado foram superiores aos outros dois tratamentos, o adubado e o inoculado, nas duas épocas de cultivo. Para o componente da produção massa de 100 grãos, não foi observada diferença significativa, e os valores encontrados foram semelhantes aos relatados por Andrade et al. (2001) em trabalho realizado com essa mesma cultivar (Ouro Negro).

A produtividade obtida na época das águas foi menor que na época da seca (Tabela 2), como também observado por Martins et al. (2009) relatando que linhagens semeadas na época da seca tiveram maiores rendimentos comparando com o cultivo das águas. Essa menor produtividade de grãos no cultivo das águas, em relação à da seca, foi provavelmente devida à ocorrência de alguns dias de temperaturas médias altas, superiores a $30{ }^{\circ} \mathrm{C}$, ocorridos no mês de novembro, e que coincidiram com o período de floração, no cultivo das águas, causando aborto de flores que, conseqüentemente, afetou o número de vagens por planta. Sob estas condições de temperaturas do ar, acima de $30^{\circ} \mathrm{C}$, têm sido observadas altas taxas de abortamento de flores e redução de produtividade, segundo Hoffmann Junior et al. (2007). Com relação à produtividade de grãos nas duas épocas, o tratamento adubado e inoculado também foi superior aos outros dois tratamentos, o adubado e o inoculado. Isso demonstra que a aplicação de $20 \mathrm{~kg}^{\mathrm{de}} \mathrm{N} \mathrm{ha}^{-1}$ na semeadura, juntamente com a inoculação, permitiu um acréscimo de produtividade, corroborando com Hungria, Campo e Mendes (2003) e Pelegrin et al. (2009). Por outro lado, a produtividade do tratamento só inoculado não diferiu do somente adubado (Tabela 2), como já observado por Bellaver e Fagundes (2009). Isso mostra que a inoculação pode substituir a dose de $20 \mathrm{~kg}$ de $\mathrm{N} \mathrm{ha}^{-1}$, em plantio não inoculado, mantendo a mesma produtividade (GRANGE et al., 2007). A maior produtividade de grãos foi obtida no tratamento adubado e inoculado, que também apresentou o maior número de vagem por planta e a maior massa seca da parte aérea (Tabela 1). Além disso, a maior massa seca da parte aérea obtida no tratamento inoculado e adubado, provavelmente ocorreu devido a um maior teor de $\mathrm{N}$ na folha, com aumento da quantidade de Rubisco, e maior atividade fotossintética e crescimento neste tratamento (LONG et al., 2006). Os resultados aqui obtidos permitem afirmar que a inoculação e adubação com $20 \mathrm{~kg}$ de $\mathrm{N}^{-1}$ ha semeadura, além de não inibir a nodulação resultou em maior produtividade de grãos, em ambas as épocas de plantio. 
Tabela 2. Número de vagens por planta, número de grãos por vagem, massa de 100 grãos e produtividade de grãos, do feijoeiro Ouro Negro, nos tratamentos adubado com $20 \mathrm{~kg} \mathrm{ha}^{-1} \mathrm{de} \mathrm{N}$ no plantio, inoculado com rizóbio, e inoculado e adubado, cultivado na época da seca e das águas.

\begin{tabular}{lcccc}
\hline Tratamentos & $\begin{array}{c}\text { Número de vagens } \\
\text { por planta }\end{array}$ & $\begin{array}{c}\text { Número de grãos } \\
\text { por vagem }\end{array}$ & $\begin{array}{c}\text { Massa de } \\
\mathbf{1 0 0} \text { grãos (g) }\end{array}$ & $\begin{array}{c}\text { Produtividade } \\
\text { de grãos (kg ha-1 }\end{array}$ \\
\hline & & Época da seca & & \\
Adubado & $7,0 \mathrm{~b}$ & $4,8 \mathrm{a}$ & $20,7 \mathrm{a}$ & $1.597 \mathrm{~b}$ \\
Inoculado & $7,2 \mathrm{~b}$ & $4,8 \mathrm{a}$ & $21,0 \mathrm{a}$ & $1.639 \mathrm{~b}$ \\
Adubado e inoculado & $8,0 \mathrm{a}$ & $5,0 \mathrm{a}$ & $20,5 \mathrm{a}$ & $1.762 \mathrm{a}$ \\
Média & 7,4 & 4,9 & 20,7 & 1.666 \\
CV (\%) & 3,89 & 4,24 & 2,41 & 9,74 \\
& & Época das águas & & \\
Adubado & $5,2 \mathrm{~b}$ & $4,9 \mathrm{a}$ & $22,0 \mathrm{a}$ & $1.282 \mathrm{~b}$ \\
Inoculado & $5,1 \mathrm{~b}$ & $4,9 \mathrm{a}$ & $22,2 \mathrm{a}$ & $1.274 \mathrm{~b}$ \\
Adubado e inoculado & $6,2 \mathrm{a}$ & $5,0 \mathrm{a}$ & $21,9 \mathrm{a}$ & $1.485 \mathrm{a}$ \\
Média & 5,5 & 4,9 & 22,0 & 1.347 \\
CV (\%) & 6,94 & 1,51 & 0,82 & 1,56 \\
\hline
\end{tabular}

Médias seguidas pela mesma letra não diferem entre si pelo teste de Tukey $(\mathrm{P}<0,05)$.

Fonte: Elaboração dos autores.

\section{Conclusões}

A inoculação de rizóbios no plantio pode substituir a adubação nitrogenada com $20 \mathrm{~kg} \mathrm{ha}^{-1} \mathrm{de}$ $\mathrm{N}$ na semeadura, sem perda de produtividade.

A adubação com $20 \mathrm{~kg} \mathrm{ha}^{-1}$ de $\mathrm{N}$ no plantio, junto com a inoculação, não inibe a nodulação da cultura do feijoeiro, além de propiciar acréscimo de massa seca de parte aérea e da produtividade.

\section{Referências}

ANDRADE, M. J. B.; LUCCA, P. A.; RESENDE, P. M.; KIKUT, H. Época de colheita em cinco cultivares de feijoeiro e efeitos sobre o rendimento de grãos e seus componentes primários. Ciência e Agrotecnologia, Lavras, v. 25, n. 1, p. 213-219, 2001.

BELLAVER, A.; FAGUNDES, R. S. Inoculação com Rhizobium tropici e uso do nitrogênio na base e por cobertura na cultura do feijoeiro (Phaseolus vulgaris L.). Cultivando o Saber, Cascavel, v. 2, p. 1-10, 2009.

CARVALHO, M. A. C.; ARF, O.; SÁ, M. O.; BUZETTI, S.; SANTOS, N. C. B.; BASSAN, D. A. Z. Produtividade e qualidade de sementes de feijoeiro (Phaseolus vulgaris L.) sob influência de parcelamentos e fontes de nitrogênio. Revista Brasileira de Ciência do Solo, Viçosa, v. 25, n. 1, p. 617-624, 2001.
CLAESSEN, M. E. C. (Org.). Manual de métodos de análise de solo. 2. ed. Rio de Janeiro: Embrapa/CNPS, 1997. 212 p. (Documentos, 1).

COSTA, G. E. A.; MONICI, K. S. Q.; REIS, S. M. P. M.; OLIVEIRA, A. C. Chemical composition, dietary fibre and resistant starch contents of raw and cooked pea, common bean, chickpea and lentil legumes. Food Chemistry, Reading, v. 94, n. 3, p. 327-330, 2006.

FARINELLI, R.; LEMOS, L. B.; PENARIO, F. G.;EGÉA, M. M.; GASPARATO, M. G. Adubação nitrogenada de cobertura no feijoeiro, em plantio direto e convencional. Pesquisa Agropecuária Brasileira, Brasília, v. 41, n. 2, p. 307-312, 2006.

FERREIRA, A. N.; ARF, O.; CARVALHO, M. A. C.; ARAÚJO, R. S.; SÁ, M. E.; BUZZET, S. Rhizobium tropici strains for inoculation of the common bean. Scientia Agricola, Piracicaba, v. 57, n. 3, p. 507-512, 2000.

GRAHAM, P. H.; VANCE, C. P. Nitrogen fixation in perspective: an overview of research and extension needs. Field Crops Research, Warwick, v. 65, n. 2-3, p. 93-106, 2000.

GRANGE, L.; HUNGRIA, M.; GRAHAM, P. H.; MARTÍNEZ-ROMERO, E. New insights into the origins and evolution of rhizobia that nodulate common bean (Phaseolus vulgaris) in Brazil. Soil Biology \& Biochemistry, Brisbaine, v. 39, n. 4, p. 867-876, 2007. 
HAWERROTH, F. J.; CRESTANI, M.; SANTOS, J. C. P. Desempenho de cultivares de feijoeiro sob inoculação com Rhizobium e relação entre os caracteres componentes do rendimento de grãos. Semina: Ciências Agrárias, Londrina, v. 32, n. 3, p. 897-908, 2011.

HUNGRIA, M.; CAMPO, R. J.; MENDES, I. C. Benefits of inoculation of the common bean (Phaseolus vulgaris) crop with efficient and competitive Rhizobium tropici strains. Biology and Fertility of Soils, Berlim, v. 39, n. 2, p. 88-93, 2003.

HOFFMANN JUNIOR, L.; RIBEIRO, N. D.; ROSA, S. S.; JOST, E.; POERSCH, N. L.; MEDEIROS, S. L. P. Resposta de cultivares de feijão à alta temperatura do ar no período reprodutivo. Ciência Rural, Santa Maria, v. 37, n. 6, p. 1543-1548, 2007.

LONG, S. P.; ZHU, X. Z.; NAIDU, S. L.; ORT, D. Can improvement in photosynthesis increase crop yields? Plant, Cell and Environment, Malden, v. 29, n. 3, p. 315330, 2006.

MARTINS, M.; FONSECA, L. F.; MELO, L. C.; OLIVERIA, D. R. F.; ALVIN, K. R.; SANTANA, D. G. Avaliação de genótipos de feijoeiro comum do grupo comercial carioca cultivados nas épocas das águas e do inverno em Uberlândia, estado de Minas Gerais. Acta Scientiarum. Agronomy, Maringá, v. 31, n. 1, p. 23-28, 2009.

OLIVEIRA, I. P.; ARAÚJO, R. S.; DUTRA, L. G. Nutrição mineral e fixação biológica de nitrogênio. In: ARAÚJO, R. S.; RAVA, C. A.; STONE, L. F.; ZIMMERMANN, M. J. de O. (Ed.). Cultura do feijoeiro comum no Brasil. Piracicaba: Potafos, 1996. p. 169-221.

PELEGRIN, R.; MERCANTE, F. M.; OTSUB, I. M. N.; OTSUB, A. A. Resposta da cultura do feijoeiro à adubação nitrogenada e à inoculação com rizóbio. Revista Brasileira de Ciência do Solo, Viçosa, v. 33, n. 1, p. 219-226, 2009.

ROMANINI JUNIOR, A.; ARF, O.; BINOTTI, F. F. S.; SÁ, M. E.; BUZETTI, S.; FERNADES, F. A. Avaliação da inoculação de rizóbio e adubação nitrogenada no desenvolvimento do feijoeiro, sob sistema plantio direto. Bioscience Journal, Uberlândia, v. 23, n. 4, p. 74-82, 2007.
SANTOS, A. B.; FAGERIA, N. K.; SILVA, O. F.; MELO, N. L. B. Resposta do feijoeiro ao manejo de nitrogênio em várzeas tropicais. Pesquisa Agropecuária Brasileira, Brasília, v. 38, n. 11, p. 1265-1271, 2003.

SILVA, T. R. B. SORATO, R. P.; CHIDI, S. N.; ARF, O.; SÁ, M. E.; BUZETTI, S. Doses e épocas de aplicação de nitrogênio em cobertura na cultura do feijoeiro de inverno. Cultura Agronomica, Ilha Solteira, v. 9, n. 1, p. 1-17, 2000.

SORATTO, R. P.; CARVALHO, M. A. C.; ARF, O. Aplicação tardia de nitrogênio no feijoeiro em sistema de plantio direto. Bragantia, Campinas, v. 64, n. 2, p. 211218, 2005.

STRALIOTTO, R. A importância da inoculação com rizóbio na cultura do feijoeiro. Seropédica: EMBRAPA Agrobiologia/CNPAB, 2002. 6 p.

TORRES, A. B.; CURSINO, L.; ABAD, J. I. M.; GOMES, E. A.; ARAUJO, E. F.; HUNGRIA, M.; CASSINI, S. T. A. Genetic diversity of indigenous common bean (Phaseolus vulgaris L.) rhizobia from the state of Minas Gerais, Brazil. Brazilian Journal of Microbiology, São Paulo, v. 40, n. 4, p. 852-856, 2009.

VALADÃO, F. C. A.; JAKELAITIS, A.; CONUS, L. A.; BORCHARTT, L.; OLIVEIRA, A. A.; VALADÃO JUNIOR, D. D. Inoculação das sementes e adubações nitrogenada e molíbdica do feijoeiro-comum, em Rolim de Moura, RO. Acta Amazonica, Manaus, v. 39, n. 4, p. 741-748, 2009.

VIEIRA, N. M. B.; ANDRADE, M. J. B.; CARVALHO, J. G. C.; ALVES JUNIOR, J.; MORAIS, A. R. Altura de planta e acúmulo de matéria seca do feijoeiro cvs. BRS MG talismã e ouro negro em plantio direto e convencional. Ciência Agrotécnica, Lavras, v. 32, n. 6, p. 1687-1693, 2008.

VIEIRA, R. F.; TSAI, S. M.; TEXEIRA, M. A. Nodulação e fixação simbiótica de nitrogênio em feijoeiro com estirpes nativas de rizóbio, em solo tratado com lodo de esgoto. Pesquisa Agropecuária Brasileira, Brasília, v. 40, p. 1047-1050, 2005.

VOISIN, A. S.; SALON, C.; JEUDY, C.; WAREMBOURG, F. R. Symbiotic $\mathrm{N}_{2}$ fixation activity in relation to $\mathrm{C}$ economy of Pisum sativum L. as a function of plant phenology. Journal of Experimental Botany, Lancaster, v. 54, n. 393, p. 2733-2744, 2003. 
